\title{
CATEGORIZACIÓN DE LOS CONFLICTOS VECINALES Y LA IMPROCEDENCIA DE INVOCAR AUTORIZACIONES ADMINISTRATIVAS Y LA OBSERVANCIA DE LEYES Y REGLAMENTOS COMO JUSTIFICACIÓN SUFICIENTE PARA VULNERAR DERECHOS DE TERCEROS. COMENTARIO A LA SENTENCIA DE LA CORTE SUPREMA, DE FECHA 15 DE MARZO DE 2018, ROL Nº 18.218-2017
}

\author{
CATEGORIZATION OF NEIGHBORHOOD CONFLICTS AND \\ THE INADMISSIBILITY OF INVOKING ADMINISTRATIVE \\ AUTHORIZATIONS OR THE OBSERVANCE OF LAWS AND \\ REGULATIONS AS ENOUGH JUSTIFICATION TO VIOLATE THE \\ RIGHTS OF THIRD PARTIES. COMMENTARY ON THE RULLING OF \\ THE SUPREME COURT, DATED MARCH 15, 2018, CASE N 18, 218-2017
}

\section{JORGE TISNÉ NIEMANN*}

RESUMEN: Recientemente la Corte Suprema se ha pronunciado sobre un conflicto de vecindad cuyo origen fue el emplazamiento de un colector de aguas lluvias que conducía y descargaba artificialmente el torrente en una propiedad vecina. Esta sentencia sirve para abordar las relaciones de vecindad como los límites de la propiedad en interés privado, distinguir entre los ataques directos e indirectos a la propiedad, y en particular, destacar que las autorizaciones administrativas y la observancia de leyes y reglamentos no son patente de corso para vulnerar derechos ajenos.

Palabras clave: Relaciones de vecindad; ataque directo a la propiedad; límites de la propiedad en interés privado; distinción entre ley y derecho ajeno como restricciones independientes al ejercicio de la propiedad.

ABSTRACT: Recently the Supreme Court has ruled on a neighborhood conflict initiated due to the implementation of a rainwater collector that artificially led and unloaded its torrent on a neighboring property. This rulling is useful to address neighborhood relations as limits of property in private interest, distinguish between direct and indirect attacks on property, and in particular, to emphasize that administrative authorizations and the compliance with laws and regulations do not justify the infringement of third party rights.

Keywords: Neighborhood relations; direct attack on property; limits of property in private interest; distinction between law and other people's rights as independent restrictions on the exercise of property.

\footnotetext{
* Doctor en Derecho, Universidad de los Andes, Chile. Abogado en Jara del Favero Abogados. Dirección Postal: El Golf 99, piso 4, Las Condes, Santiago. Dirección electrónica: jtisne@jdf.cl. El autor agradece el continuo entusiasmo y apoyo de Claudia Poblete.
} 


\section{INTRODUCCIÓN}

Las relaciones de vecindad son un campo permanente de conflictos. Estas se basan en el principio que la propiedad se presume libre e inviolable, y en base a ello, el vecino puede rechazar toda intromisión de terceros, salvo que existan razones de orden público o privado que exijan su tolerancia.

El Código Civil chileno de 1857 las abordó desde una óptica clásica, a semejanza de su par francés de 1804. Los ejemplos y regulaciones de los conflictos de vecindad normados por el Código Civil son reflejo del estado de industrialización de la época de su redacción (conflictos propios de su tiempo), caracterizados por la inmediatez de los predios involucrados, los propietarios como únicos sujetos capaces de intervenir y la propiedad como bien jurídico exclusivo de protección.

En la actualidad dicho concepto clásico de vecindad ha sido superado por la nueva variedad de conflictos a los que se enfrentan los vecinos, lo que exige entender las relaciones de vecindad desde una óptica moderna, caracterizada por la ampliación de los sujetos intervinientes, la superación de la inmediatez por la zona de influencia y el reemplazo de la protección dominical por el resguardo del tranquilo ejercicio de facultades materiales en los inmuebles.

Con todo, lo anterior no es óbice para afirmar que las reglas que se pueden extraer de los actuales supuestos normativos contemplados por el Código Civil, así como las soluciones que propone para los conflictos regulados, sumado a una relectura moderna de las relaciones de vecindad, admiten encontrar en su libro II suficiente sustento dogmático y legal para resolver los conflictos que actualmente tensan las relaciones de vecindad, sean ataques directos o indirectos (inmisiones) a la propiedad.

Es conveniente precisar que previo al conflicto vecinal (el cual permite definir una relación jurídica de vecindad entre sujetos determinados), la simple vecindad impone deberes de pleno derecho a quienes intervienen en ella. Así, deben cumplir con los deberes jurídicos en sentido amplio y con un deber genérico de abstención. El primer deber dice relación con el cumplimiento de los supuestos normativos que regulan las relaciones de vecindad, y el segundo, se refiere al deber de abstención que deben observar los vecinos para no perturbar o molestar a otro mediante el ejercicio de su derecho de propiedad.

Como se ha planteado en doctrina comparada, estos deberes serían "relaciones de comunidad de intereses entre propietarios de fincas vecinas' -que- son relaciones obligatorias nacidas ex lege por el hecho de producirse una relación social especial, de la que se derivan particulares deberes recíprocos de tolerancia y de conducta" ${ }^{1}$.

Los deberes que impone la vecindad constituyen límites específicos o extrínsecos al ejercicio de la propiedad en interés privado. Estos límites, también llamados confín normal del derecho de propiedad, encuentran en la vecindad su reflejo más conspicuo ${ }^{2}$. Por lo tanto, desde la perspectiva de los intereses privados, el ejercicio de la propiedad está naturalmente delimitado y ordenado en virtud de los deberes que impone la vecindad. La

\footnotetext{
1 WestermanN (1998) p. 855.

2 Confróntese Pescio VArgas (1950) p. 311
} 
transgresión de dichos deberes faculta al vecino afectado a ejercer las acciones civiles para restablecer dichos deberes, y de esta manera, cesar o reparar los perjuicios que le ha producido la transgresión de la esfera interna de su propiedad ${ }^{3}$.

\section{DESCRIPCIÓN DEL CASO}

Con fecha 30 de diciembre de 2016, diversas personas recurren de protección ante la Corte de Apelaciones de Puerto Montt, en contra de la Inmobiliaria Socovesa Sur S.A. con el objeto que se acoja y se ordene cegar el ducto de agua que ilegalmente inunda la propiedad de los recurrentes, con costas.

Los recurrentes declaran ser dueños en común de una hijuela de 28 hectáreas, en la ciudad de Puerto Montt. Cabe destacar que en el año 2012, vendieron un lote de 8 hectáreas a Inmobiliaria GPR, la cual construyó una villa de viviendas y habilitaron una calle denominada Monseñor J. Hourton, que actualmente es el deslinde entre dicha propiedad y la de los recurrentes.

En un lugar cercano, la recurrida se encontraba desarrollando un conjunto habitacional en un lugar de su dominio (en adelante el "Condominio"). Los recurrentes denunciaron que la recurrida, para efectos de canalizar aguas lluvia y otros escurrimientos de aguas proveniente del Condominio, instaló un ducto que dirigía artificialmente dichas aguas hacia un estero emplazado al interior de su propiedad, sin contar con las autorizaciones necesarias y alterando el escurrimiento natural de las aguas. Esgrimieron que tal acto constituía un acto ilegal y arbitrario que vulneraba su derecho de propiedad.

La recurrida sostuvo distintos argumentos para solicitar la inadmisibilidad del recurso. En lo que aquí interesa, señala que el proyecto de evacuación de aguas lluvia ha sido aprobado, autorizado y recepcionado por todos los organismos públicos competentes, que nace en el Condominio en ejecución y finaliza en una conexión a una cámara de un colector existente construido por la empresa Inmobiliaria GPR entre los años 2013 y 2014, el cual ya ha sido recepcionado y que se sitúa en la Av. Monseñor Jorge Hourton. Alega que las obras de urbanización del Condominio fueron recepcionadas mediante Certificado de Recepción Definitiva de Obras de Urbanización, de fecha 21 de diciembre de 2016, emitido por la Dirección de Obras Municipales de Puerto Montt.

Con fecha 26 de abril de 2017, en RODRÍGUEZ Y OTROS CON INMOBILIARIA SOCOVESA SUR S.A. (2017), se rechaza el recurso de protección debido a que no tuvo por acreditado fehacientemente que el escurrimiento de las aguas lluvias hacia terrenos de los recurrentes tuvieran su origen directo en la actuación de la recurrida, agregando que respecto de dichas obras existe una recepción del Servicios de Vivienda y Urbanización (SERVIU), y además cuenta con la recepción definitiva por parte de la Dirección de Obras Municipales de Puerto Montt. Asimismo, funda su resolución en que la Dirección General de Aguas, Región de Los Lagos, informó que cerca de las coordenadas denunciadas por los recurrentes, la Inmobiliaria GPR Puerto Varas había ejecutado una obra de tubería de 1000 $\mathrm{mm}$. de diámetro, sin muro de boca u otra obra de soporte y que descansaba sobre el cauce

3 Sobre las relaciones de vecindad ver TiSNÉ NIEMANN (2017) pp. 16-138. 
de un estero sin nombre, por lo que no existe certeza del origen del escurrimiento de aguas denunciado, escapando al procedimiento de la acción cautelar.

Los recurrentes interponen recurso de apelación contra dicha sentencia, en virtud del cual la Corte Suprema en RODRÍGUEZ Y OTROS CON INMOBILIARIA SOCOVESA SUR S.A. (2018) concluye: "[q]ue de los antecedentes descritos en el motivo noveno que antecede, se advierte que el predio de los actores está recibiendo no sólo la descarga de aguas lluvia provenientes del proyecto inmobiliario de la empresa GPR, sino que además, de aquel desarrollado por Socovesa del Sur S. A. que, según afirma, se adosó al sistema de evacuación construido por aquélla mediante tuberías de $600 \mathrm{~mm}$, sin perjuicio de la existencia de otras uniones particulares sobre las que la autoridad carece de antecedentes, produciéndose una afectación no sólo para aquéllos por la inundación del predio contiguo, sino que además, un potencial riesgo de desborde en un sector cercano a una zona urbana, en particular, porque no existe un estudio referente a la capacidad de agua que el estero puede soportar, debiendo considerarse que tal riesgo se ve asimismo representado de forma objetiva al tener en consideración las 247 viviendas ya construidas por la empresa GPR, junto a las 50 proyectadas -según consigna en su informe- y aquellas que Socovesa actualmente tiene a la venta en su proyecto Condominio Mirador II, capacidad de soporte y traslado de aguas del aludido estero que no ha sido catastrado como tal por la autoridad, añadiéndose a lo anterior la extrañeza causada en la Dirección de Obras Municipales, al detectar que aquel cauce de agua desembocaba en un sitio particular, no obstante ser parte del sistema general de evacuación de aguas lluvia de Puerto Montt"^.

Dado lo anterior, la Corte Suprema revoca la sentencia apelada y en su lugar acoge el recurso de protección, ordenando que en el plazo de tres meses la recurrida constituya la servidumbre que en derecho corresponda en el predio de los recurrentes, cumpliendo además con las disposiciones legales y reglamentarias pertinentes, bajo aparecimiento de ordenarse el cierre del ducto que las evacua en ese lugar.

\section{COMENTARIO DE JURISPRUDENCIA}

Ceñiremos este comentario de jurisprudencia a dos elementos. El primero dice relación con el tipo de ataque a la propiedad que evidencia el supuesto fáctico que origina el conflicto objeto del recurso de protección. El segundo es respecto al argumento esgrimido por la Corte Suprema en cuanto a que las autorizaciones administrativas no justifican la afectación de derechos subjetivos de terceros.

\subsection{CATEgORIZACión DEL CONFLICTO VECINAL OBJETO DEL CASO EN COMENTO}

El supuesto fáctico que ha sido desarrollado previamente supone entender que estamos en el marco de las relaciones de vecindad, toda vez que este cumple con los presupuestos de las relaciones de vecindad. En primer lugar, existe entre recurrentes y recurrida convivencia al ser titulares de predios próximos; cercanía que revela el presupuesto social de las relaciones de vecindad. En segundo lugar, ambas partes aprovechan de forma permanente

4 RODRÍGUEZ Y OTROS CON INMOBILIARIA SOCOVESA SUR S.A. (2018), considerando duodécimo. 
los inmuebles de los cuales son propietarios, siendo esto fundamento del presupuesto jurídico de las relaciones de vecindad. Finalmente, la existencia de un conflicto jurídicamente relevante que deteriora la normal convivencia (expresado en la existencia del ducto que inunda el inmueble vecino) constituye el tercer presupuesto de las relaciones de vecindad.

Encontrándose presentes los tres presupuestos, podemos afirmar que existe una verdadera relación jurídica de vecindad, pues el conflicto surge a raíz del ejercicio de los derechos de propiedad de cada dueño en su respectivo predio. Por una parte, el demandado pretende ejercer su derecho de propiedad mediante la instalación y operación del ducto de agua (derecho a usar lo suyo). Por el otro lado, los recurrentes pretenden defender su dominio frente a lo que consideran una invasión ilegítima de la esfera interna de su propiedad (derecho a excluir a otros de lo suyo). En otras palabras, la colisión de derechos se funda en el mutuo disfrute de las propiedades por parte de los recurrentes y la recurrida.

Ahora bien, los conflictos que surgen en las relaciones de vecindad pueden ser clasificados en dos categorías. La primera son los ataques directos y las segunda son ataques indirectos (propiamente inmisiones).

En este comentario nos centraremos en los primeros, pues la existencia de un colector que conduce artificialmente las aguas de dos predios, depositándolas en la propiedad de un tercero, constituye un ejemplo de ataque directo a la propiedad.

Los ataques directos a la propiedad se caracterizan por ser hechos que vulneran la esfera interna de una propiedad ajena mediante el ingreso no autorizado de una persona, cosa o mediante un ducto especial. Todos estos elementos transgreden los límites materiales de la propiedad vecina. Dado lo anterior, el ataque directo a la propiedad se entiende como un facere in alieno, pues consiste en un hacer directo sobre la cosa (inmueble) de un tercero. Debido a que este tipo de ataque consiste en un traspaso directo de los límites materiales inmobiliarios, las vías mediante las cuales se materializa este tipo de ataque suelen ser evidentes, materiales y objetivas.

Las distintas disposiciones contenidas en el Código Civil denotan que este reguló especialmente los ataques directos a la propiedad (en desmedro de las inmisiones). Esto se explica por su época de redacción y por haber sido informado especialmente en materia de servidumbres por el Código Civil francés de $1804^{5}$. De los supuestos normativos previstos en nuestro Código Civil, se extrae la regla que el ataque directo siempre es ilícito, y por tanto no debe ser tolerado ${ }^{6}$, salvo que exista la autorización del vecino para desarrollar dicha actividad o una disposición legal que así lo admita ${ }^{7}$.

En atención a esta regla, se puede afirmar que el Código Civil contiene suficiente fundamento legal para afirmar que la existencia de un colector de agua que atraviesa el plano vertical de un inmueble ajeno, sin previa autorización del vecino y sin que exista causal legal que lo permita, debe ser considero un hecho ilícito, y por lo tanto, constitu-

\footnotetext{
5 El Mensaje del Código Civil enseña que "en la interesante materia de las servidumbres se ha seguido, se puede decir, paso a paso el Código Civil francés”.

6 Lo anterior se puede extraer del Código Civil, artículos 609, 610, 612, 613, 615, 616 y 617.

7 En este sentido, Código Civil, artículos 620, 627, 930 y 943.
} 
ye una vulneración del derecho de propiedad del vecino que recibe el torrente canalizado artificialmente.

De hecho, la Corte Suprema confirma lo anterior en el siguiente considerando: "Que en consecuencia, la inundación que enfrenta parte del inmueble de propiedad de los actores proviene directamente de la excesiva descarga de aguas lluvia en el estero emplazado al interior de su predio, obras ejecutadas en contravención a lo dispuesto en los artículos 171 del Código de Aguas y 582 del Código Civil, por cuanto se les impide ejercer plenamente las facultades de uso, goce y disposición de las que son titulares, extendiéndose en particular la afectación a la dificultad que pudiera generarse en cuanto al provecho económico que quisieran obtener si se advierte que el predio está inundado y que a futuro, podría estarlo aún más tras concluir los proyectos inmobiliarios proyectados y en construcción y se recubra permanentemente el suelo que absorbía el exceso de lluvia, que de esta forma será conducido mediante obras de canalización cuyo trayecto concluirá, como hasta ahora lo hace, aunque en mayor cantidad, en el inmueble de propiedad de los demandantes" 8 .

El conflicto vecinal en comento se explica por la existencia de un ducto de agua emplazado en propiedad de la recurrida, el cual finalizaba en una conexión con un colector ya existente construido por la Inmobiliaria GPR años antes. Este colector constituye un conducto especial subterráneo a través del cual se atravesó el límite material de un inmueble ajeno. Si bien el Código Civil no contiene una disposición que explícitamente prohíba dicha obra (a diferencia del artículo 931 inciso tercero que considera especialmente denunciables las obras voladizas), sí encontramos en cuerpos civiles comparados una referencia explícita a esta prohibición. Este es el caso del Código Civil alemán", el Código Civil austriaco $^{10}$ y el Código Civil de Cataluña, España ${ }^{11}$.

A mayor abundamiento, la doctrina española es conteste en considerar que los ataques directos no deben ser tolerados ${ }^{12}$. Por otro lado, se ha planteado el rechazo a los ataques directos de manera enfática al mencionar que "los elementos corpóreos de gran tamaño [...] no deberán ser tolerados en ningún caso, por más que no entorpezcan esencialmente el aprovechamiento de la finca que los sufre o que sea algo acostumbrado en el lugar [...]"13, y específicamente en lo que nos interesa en este comentario, "lo mismo cabe decir de desagües"14.

\footnotetext{
8 RODRÍGUEZ Y OTROS CON INMOBILIARIA SOCOVESA SUR S.A. (2018), considerando decimotercero.

9 Código Civil alemán, artículo 906 inciso final: "La intrusión por un conducto especial no es permisible".

10 Código Civil austriaco, artículo 363 inciso segundo: "El propietario de un bien inmueble puede prohibir los efectos que provengan del vecino mediante las aguas residuales, el humo, el gas, el calor, los olores, el ruido, las sacudidas y otras cosas similares en la medida que excedan los límites acostumbrados según parámetros locales y que perjudiquen sustancialmente el uso local del terreno. La transmisión directa es inadmisible bajo toda circunstancia a falta de un título jurídico" (el destacado es nuestro).

11 Código Civil de Cataluña, España, artículo 546-14 Nº: "Ningún propietario o propietaria está obligado a tolerar inmisiones dirigidas especial o artificialmente hacia su propiedad”.

12 Por todos, Jiménez SalCedo (1999) p. 39.

13 Westermann (1998) p. 831.

14 Westermann (1998) p. 831.
} 


\subsection{LA AUTORIZACIÓN ADMINISTRATIVA NO JUSTIFICA LA AFECTACIÓN DE DERECHOS AJENOS}

La Corte Suprema decide revocar la sentencia de la Corte de Apelaciones de Puerto Montt y acoger el recurso de protección interpuesto por los recurrentes, en especial, al considerar que el emplazamiento del ducto por parte de la recurrida fue ilegal y que existían elementos suficientes para imputar objetivamente a esta la causación de los daños a propósito de la inexistencia de un registro en el catastro que al efecto lleva la Dirección General de Aguas referentes a las obras denunciadas ${ }^{15}$.

Sin perjuicio de lo anterior, la recurrida esgrimió como defensa que el ducto adosado al colector existente contaba con la autorización y recepción de los organismos públicos competentes, toda vez que el SERVIU regional aprobó el año 2013 el colector emplazado por la constructora GPR, obra que fue recibida definitivamente por la Dirección de Obras Municipales en agosto 2014.

Ante dicho argumento, la Corte Suprema recogió una distinción dogmática de principios de siglo XX que consideramos valiosa de rescatar y comentar. En este sentido la Corte expuso: "Que en cuanto a las autorizaciones administrativas que para la recurrida constituirían suficiente amparo y justificación de su actuación, misma alegación que en su favor efectúa la Inmobiliaria GPR, debe ser descartada por cuanto aquella no la habilita para perjudicar a terceros, es decir, no se puede tolerar la lesión de derechos subjetivos o intereses particulares en una medida no contenida en la normativa vigente o por el uso social o la razón, porque, en caso contrario, el desarrollo de dichas actividades justificada en tales concesiones constituiría un abuso del derecho. En este sentido, la autorización es un asunto que sólo concierne a la relación entre la Administración y el administrado, que no puede ser el criterio que fundamente las relaciones entre particulares con exclusión de la aplicación de las normas del Derecho Civil concernientes al caso, por cuanto el permiso otorgado

15 RODRÍGUEZ Y OTROS CON INMOBILIARIA SOCOVESA SUR S.A. (2018), considerando decimoséptimo.

La Corte Suprema llega a esta conclusión al corroborar que la recurrida tuvo responsabilidad en los hechos denunciados pues ejecutó "una profunda perforación y alteración del curso natural de las aguas sin la obtención de los permisos necesarios y obligatorios, puesto que las ejecutó mediante la conexión de un ducto que las canaliza artificialmente" (considerando decimosexto).

Lo anterior quedó refrendado con el informe evacuado por el Director del SERVIU de la Región de Los Lagos, que explica los problemas que podrían surgir del foso ejecutado por la recurrida y del ducto emplazado que atraviesa el camino, carente de las características técnicas para conducir el torrente, "por cuanto la tubería de descarga es inferior a la reglamentaria, provocando un estrangulamiento y eventual desborde de las aguas, obras que no responden a ningún estudio aprobado por un órgano público" (considerando decimosexto).

Además, no existía en el Catastro Público de Aguas de la Dirección General de Aguas un proyecto aprobado para el emplazamiento del ducto de la recurrida, constituyendo una contravención a lo establecido en los artículos 41 y 171 del Código de Aguas. Dichos artículos disponen que las modificaciones de cauces naturales o artificiales deberán ser aprobadas previamente por la Dirección General de Aguas, entendiéndose por modificaciones, entre otras, la alteración de cualquiera de sus obras y la construcción de nuevas, como también cualquiera que tenga por finalidad la sustitución o complemento de las obras.

A pesar que el ducto de la recurrida nació en el Condominio de su propiedad y que finalizaba en una conexión a la cámara de un colector existente construido previamente por la empresa Inmobiliaria GPR, la Corte Suprema determina que la obligación de obtener dichos permisos con anterioridad a la ejecución de la modificación de las obras existentes concernía tanto a la constructora GPR como a Socovesa del Sur S.A., por lo que su omisión fue inexcusable para ambas empresas (considerando decimotercero). 
no significa disponer de una potestad ilimitada que incluya la afectación de un derecho del que un tercero ajeno a esa relación sea titular" 16 .

Concordamos con la Corte Suprema en que los permisos o autorizaciones administrativas para ejecutar o desarrollar una actividad no pueden constituir justificación alguna para afectar los derechos de terceras personas. El permiso o autorización es una relación entre la Administración y el administrado, que en nada altera los derechos ajenos, en particular de los propietarios vecinos del titular del permiso.

Tanto permisos administrativos como derechos subjetivos de terceros operan en ámbitos del Derecho disímiles. Por un lado, permisos o autorizaciones administrativas son de orden público. Los derechos de terceras personas, incluidos los vecinos, son de orden privado. Es por eso que la Corte correctamente señala que la autorización administrativa no es el criterio en base al cual los particulares deben estructurar su convivencia, pues en este ámbito, operan las normas del Derecho Civil.

Esta distinción, que no se observa con frecuencia en la jurisprudencia nacional, encuentra fundamento legal en el artículo 582 inciso primero del Código Civil el cual dispone: "El dominio (que se llama también propiedad) es el derecho real en una cosa corporal, para gozar y disponer de ella arbitrariamente; no siendo contra la ley o contra derecho ajeno". Recordemos que la Corte Suprema indicó dicho artículo como un derecho vulnerado por la actuación de la recurrida ${ }^{17}$.

La distinción hecha valer por la Corte Suprema encuentra fundamento legal en la coletilla "no siendo contra ley o contra derecho ajeno". Ambas restricciones al ejercicio de la propiedad son independientes, sin que el legislador las haya subordinado la una a la otra, por lo que es correcto entenderlas como restricciones de idéntica jerarquía y relevancia. Las autorizaciones administrativas requeridas por el ordenamiento para la ejecución y operación de una actividad pueden subsumirse dentro del vocablo ley. En la medida que el titular de la actividad obtenga los permisos o autorizaciones que el ordenamiento exige, estará en cumplimiento de la primera restricción que impone el artículo 582 del Código Civil, la cual se explica a propósito del resguardo de los intereses generales.

Sin embargo, el titular de la actividad no solo debe cumplir con la ley sino también con el derecho ajeno como restricción al ejercicio de la propiedad. El derecho ajeno en materia de propiedad cumple el rol de compatibilizar su ejercicio en distintos inmuebles en resguardo de los intereses privados.

La ley es expresión de una función social pública de la propiedad (responde a intereses generales). El derecho ajeno es expresión de una función social privada de la propiedad (responde a intereses particulares). Ello denota que el Código Civil chileno desde un comienzo consagró la distinción entre los intereses públicos y los privados como restricciones independientes y de idéntica relevancia al ejercicio de la propiedad ${ }^{18}$.

\footnotetext{
16 RODRIGGUEZ Y OTROS CON INMOBILIARIA SOCOVESA SUR S.A. (2018), considerando decimocuarto.

17 RODRÍGUEZ Y OTROS CON INMOBILIARIA SOCOVESA SUR S.A. (2018), considerando decimotercero.

18 Esta doble limitación existe y ha sido reconocida en cuerpos normativos comparados. En este sentido, HEDEMANN (1955) p. 140 rescata la "duplicidad de caras" del artículo 903 del Código Civil alemán al disponer que la propiedad se puede ejercer discrecionalmente "en tanto no se oponga a la ley o los derechos de terceros".
} 
Mientras la ley es fuente de restricciones normativas concretas, en el derecho ajeno subyace el principio que nadie puede hacer en lo suyo aquello que perjudique o dañe a otros (determinación específica del principio alterum non laedere en materia de vecindad). Por lo tanto, todo propietario (o vecino) debe abstenerse de ejercer el derecho de una manera que dañe o perturbe a terceros, más allá de las restricciones legales que imponga el ordenamiento (incluyendo la obtención de permisos o autorizaciones administrativas) ${ }^{19}$.

Con el objeto de refrendar su postura, la Corte Suprema citó el siguiente párrafo de Claro Solar: "no serviría de excusa al propietario que causa el perjuicio o molestia al vecino, haber obtenido de la autoridad administrativa el permiso que los reglamentos exigen para la instalación de ciertos negocios o industrias, fábricas o usinas. Tal autorización no podría poner a cubierto al industrial de la acción civil de sus vecinos"20.

Esta cita es clara respecto de la distinción entre el ámbito de aplicación del derecho público y el derecho privado en las relaciones de vecindad. En esta materia, los deberes que impone la vecindad exigen que los intervinientes (vecinos) siempre resguarden la igualdad y reciprocidad que debe imperar en esta disciplina. Es por eso que, más allá de los permisos administrativos obtenidos y del cumplimiento de las disposiciones legales o reglamentarias atingentes, el titular de la actividad deberá abstenerse de quebrantar los deberes que impone la vecindad, toda vez que el respeto al derecho ajeno como explícita restricción legal al ejercicio de la propiedad en interés privado es un imperativo para desarrollar cualquier actividad lícitamente.

A las palabras de Claro Solar podemos agregar, en doctrina nacional, las de Alessandri Rodríguez, quien expuso: "La responsabilidad del propietario, del industrial o del comerciante existe, aunque su industria, negocio o establecimiento funcione autorizado por la ley o la autoridad administrativa o en virtud de una concesión legalmente otorgada y con observancia de todas las medidas legales o reglamentarias señaladas al efecto o que la prudencia aconseje [...] Tal responsabilidad subsiste no obstante estas circunstancias, porque ella proviene de no adoptar las medidas necesarias para evitar que el funcionamiento de la fábrica, establecimiento o negocio irrogue daños o molestias superiores a los tolerables, en exceder, a causa de esa omisión, el límite ordinario de las relaciones de vecindad. De ahí por qué ni la autorización legal o administrativa, ni la observancia de leyes o reglamentos eximen de ella: éstos se limitan a señalar las medidas destinadas a proteger el interés general; pero no impiden o prohíben que el interesado adopte las demás que en cada caso particular sean menester para evitar que su acto dañe a otros" 21 .

La improcedencia de sostener que las autorizaciones administrativas constituyen una justificación plausible para ignorar al Derecho Civil en cuanto rama que regula la relación

19 Con mayor detalle hemos analizado el derecho ajeno como límite de la propiedad en TISNÉ NIEMANN (2017) pp. 105-126. Sobre la definición de propiedad también AMUNÁTEGUI PERELLÓ (2013) pp. 5-20.

20 Claro Solar (1930) p. 354. Citado en RODRÍGUEZ Y OTROS CON INMOBILIARIA SOCOVESA SUR S.A.

(2018), considerando decimoquinto.

21 Alessandri RodrígueZ (2005) pp. 200-201. 
entre privados ha sido frecuentemente refrendada en doctrina comparada ${ }^{22}$. Incluso, esto ha sido expresamente consagrado en Códigos Civiles latinoamericanos, como es el caso del Código Civil y Comercial argentino ${ }^{23}$ y el Código Civil paraguayo ${ }^{24}$.

A mayor abundamiento, la Corte Suprema funda la imposibilidad de que las autorizaciones administrativas puedan ser entendidas como permisos que admiten todo tipo de actividad para su titular, inclusive aquellas que afecten derechos ajenos, en el artículo 52 de la ley $\mathrm{N}^{\circ} 19.880^{25}$. Lo anterior coincide con la doctrina nacional que ha abordado la teoría de las inmisiones ${ }^{26}$.

En el mismo sentido se puede interpretar lo señalado por la Contraloría General de la República en materia ambiental, pues si bien reconoce que la Resolución de Calificación Ambiental de un proyecto constata su cumplimiento con la legislación ambiental, ello no obsta a que el resto de la normativa vigente pueda ser aplicada al proyecto ${ }^{27}$. Luego, utilizando el mismo argumento, si bien un proyecto puede tener las autorizaciones que leyes o reglamentos ambientales, urbanísticos o de otra índole exijan para su funcionamiento, ello no otorga un derecho ni justifica que el titular de dichas autorizaciones vulnere derechos subjetivos de terceros, pues ello implicaría la transgresión del artículo 582 del Código Civil

22 Solo a modo de ejemplo, en España, Embid Tello (2010) p. 540; Algarra Prats (2004) p. 110; Hualde MANSO (2004) p. 180; CuAdrado PÉREZ (2005) p. 86; EVANGElio LlorCa (2000) p. 241; Amat Llari (1990) p. 79. En Alemania, Westermann (1998) p. 840. En Chile Amunátegui Perelló (2012) p. 79.

23 Código Civil y Comercial argentino, artículo 1973 inciso primero: "Las molestias que ocasionan el humo, calor, olores, luminosidad, ruidos, vibraciones o inmisiones similares por el ejercicio de actividades en inmuebles vecinos, no deben exceder la normal tolerancia teniendo en cuenta las condiciones del lugar y aunque medie autorización administrativa para aquéllas" (el destacado es nuestro).

24 Código Civil paraguayo, artículo 2000: "El propietario está obligado, en el ejercicio de su derecho, especialmente en los trabajos de explotación industrial, a abstenerse de todo exceso en detrimento de la propiedad de los vecinos. Quedan prohibidos en particular las emisiones de humo o de hollín, las emanaciones nocivas y molestas, los ruidos, las trepidaciones de efecto perjudicial y que excedan los límites de la tolerancia que se deben los vecinos en consideración al uso local, a la situación y a la naturaleza de los inmuebles. El propietario, inquilino o usufructuario de un predio tiene el derecho a impedir que el mal uso de la propiedad vecina pueda perjudicar la seguridad, el sosiego y la salud de los que habitan.

Según la circunstancia del caso, el juez puede disponer la cesación de tales molestias y la indemnización de los daños, aunque mediare autorización administrativa” (el destacado es nuestro).

25 En este sentido, RODRÍGUEZ Y OTROS CON INMOBILIARIA SOCOVESA SUR S.A. (2018), considerando decimoquinto: "Por lo expuesto, en nuestro ordenamiento las autorizaciones administrativas no pueden estimarse permisivas para realizar toda clase de actos o entenderse como suficiente justificación, incluso en perjuicio de terceros, proscripción que además se contiene en el artículo 52 de la Ley $\mathrm{N}^{\circ} 19.880$, que impone como límite de los actos administrativos la lesión de derechos de terceros, por lo que no podría estimarse que la autorización faculta a su titular para mermarlos".

26 Amunátegui Perelló (2013) pp. 83-84; Tisné Niemann (2017) pp. 218-219. El artículo 52 de la ley N 19.880 de 2003 dispone: "Retroactividad. Los actos administrativos no tendrán efecto retroactivo, salvo cuando produzcan consecuencias favorables para los interesados y no lesionen derechos de terceros".

27 Contraloría General de la República, Dictamen 2192 del 2014, párrafo 15: "[s]in perjuicio de lo anterior, en relación a lo argumentado por el recurrente en orden a que la resolución exenta $N^{\circ} 134$, de 2009 , de la Comisión Regional del Medio Ambiente de la Región del Bío Bío, le habría otorgado un derecho adquirido para desarrollar los trabajos, cabe manifestar que si bien dicho acto da cuenta que la actividad sometida cumple con la legislación desde el punto de vista ambiental, en ningún caso exime a su titular de la observancia del resto de la normativa vigente que sea pertinente para la ejecución de la misma, como acontece con las normas de uso de suelo aplicables en el área requerida”. 
(desde un punto de vista civil) y del artículo 52 de la ley $\mathrm{N}^{\circ} 19.880$ (desde un punto de vista administrativo).

A modo de ejemplo, un caso en el cual la aplicación de este criterio habría conducido a la Corte de Apelaciones de Puerto Montt a analizar la afectación de los derechos de los terceros, más allá de la legalidad de la actividad, es en RUIZ CON RESTAURANT COMIDA Y SABOR Y OTROS (2015). En este recurso de protección, los recurrentes (vecinos) denunciaban los altos volúmenes de ruidos a los que se veían expuestos a propósito de la música que proyectaban distintos locales comerciales ubicados en las inmediaciones de sus hogares. En particular, indicaron vulnerados sus derechos constitucionales a la integridad física y psíquica (artículo $19 \mathrm{~N}^{\circ} 1$ ), el derecho a vivir en un medio ambiente libre de contaminación (artículo $19 \mathrm{~N}^{\circ}$ 8) y su derecho de propiedad (artículo $19 \mathrm{~N}^{\circ} 24$ ).

La Corte rechaza el recurso aduciendo que todas las recurridas tienen patentes comerciales y su giro es el de restaurant, por lo que "se encuentran autorizadas por la entidad edilicia para ejercer su actividad comercial, la cual en virtud de lo dispuesto en el artículo 3 letra c) de la Ley 19.925 comprende también tener música en vivo, en la medida que se desarrollen dentro del horario de funcionamiento permitido por el artículo 21 del mismo cuerpo legal, esto es, de 22:00 horas a 04:00 horas" 28 . Asimismo "no se ha logrado acreditar que se provoquen ruidos fuera de lo reglamentariamente aceptado a la fecha" 29 .

En atención al criterio aquí comentado, la Corte de Apelaciones de Puerto Montt debería haber analizado si la actividad cumplía con las dos restricciones contempladas por artículo 582 del Código Civil al ejercicio del dominio. Si bien la Corte llega a la convicción que la actividad ruidosa era legal (cumplían con las autorizaciones administrativas necesarias y no se acreditó la superación de los límites de emisión reglamentarios), nada mencionó respecto a la afectación del derecho ajeno de los recurrentes, siendo esta una restricción independiente a la ley como límite al ejercicio de la propiedad de las recurridas.

\section{CONCLUSIÓN}

La sentencia objeto del presente comentario de jurisprudencia ha servido para retomar la disciplina civil de las relaciones de vecindad, y en particular, ahondar en la categorización de los conflictos vecinales y en la distinción entre autorizaciones administrativas y los derechos subjetivos de particulares.

El primer punto examinado, esto es, la categorización de los conflictos vecinales, permite distinguir entre los ataques directos y los indirectos (propiamente inmisiones) a la propiedad, centrando el comentario en los primeros, toda vez que el supuesto fáctico descrito por la sentencia y que origina el conflicto, corresponde dogmáticamente a un ataque directo a la propiedad (ingreso no autorizado a un predio vecino mediante un ducto especial).

Si bien el Código Civil chileno no contiene una disposición expresa que confirme o rechace la ilicitud de este tipo de ataque inmobiliario, de diversas disposiciones de dicho

28 RUIZ CON RESTAURANT COMIDA Y SABOR Y OTROS (2015), considerando cuarto.

29 RUIZ CON RESTAURANT COMIDA Y SABOR Y OTROS (2015), considerando quinto. 
cuerpo legal es posible extraer la regla que un facere in alieno siempre es ilícito, salvo que exista autorización del dueño o causal legal que lo autorice.

El segundo punto examinado, esto es, la distinción entre autorizaciones administrativas y derechos subjetivos de terceros, es a nuestro juicio un importante precedente que sienta la Corte Suprema, al rescatar una doctrina de principio de siglo XX que tiene la aptitud de tener una aplicación relevante en materia urbanística, ambiental y vecinal.

Esta doctrina dispone que los permisos o autorizaciones administrativas constituyan una relación exclusiva entre la Administración y el administrado, sin que ello admita la afectación de los derechos subjetivos de terceras personas que no han sido parte de esa relación. En otras palabras, el hecho de contar con las autorizaciones administrativas exigidas por el ordenamiento para la implementación y ejecución de una actividad no es patente de corso para perjudicar o dañar los derechos ajenos.

Esta interpretación puede ser extrapolada del artículo 582 del Código Civil chileno, en cuanto a que la propiedad se puede gozar y disponer arbitrariamente, no siendo contra ley o derecho ajeno. Del concepto de derecho ajeno, como límite independiente a la ley en el ejercicio del derecho, se puede inferir el principio que nadie puede hacer en lo suyo aquello que perjudique o dañe a otros.

Al existir una consagración expresa en el Código Civil sobre dos restricciones independientes al ejercicio de la propiedad, toda actividad debe cumplir con las exigencias legales de un proyecto, y además, evitar dañar o perturbar a los terceros. La infracción a cualquiera de las dos restricciones devendrá en la ilicitud de la actividad. Por lo tanto, en materia de vecindad, el derecho ajeno corresponde a un deber de abstención que deberá observar todo vecino para evitar menoscabar los derechos de quienes aprovechan inmuebles cercanos, más allá de las autorizaciones administrativas que le sean exigibles o la observancia de leyes o reglamentos. A mayor abundamiento, la Corte Suprema funda este criterio en el artículo 52 de la Ley $\mathrm{N}^{\circ} 19.880$ de 2003.

La aplicación práctica de esta distinción es relevante en materia vecinal, urbanística y ambiental. Cuando el titular de una actividad afecte derechos subjetivos ajenos, con independencia de que haya obtenido las autorizaciones administrativas pertinentes o que la actividad cumpla con los parámetros legales o reglamentarios vigentes, los tribunales ordinarios de justicia podrán conocer de dicha controversia y adoptar las medidas necesarias para restablecer los deberes que impone la vecindad. Para ello, los jueces deben resolver la licitud de la actividad en base a su legalidad (no siendo contra la ley) y la no afectación de los derechos subjetivos de terceros (no siendo contra derecho ajeno).

\section{BIBLIOGRAFÍA CITADA}

AleSSANDri RodrígueZ, Arturo (2005): De la responsabilidad extracontractual en el derecho civil chileno (Santiago, Editorial Jurídica de Chile).

Algarra Prats, Esther (2004): "La lucha jurídica contra el ruido y el derecho civil" en GonZÁlez Porras, José Manuel y MÉndez GonZÁlez, Fernando (coordinadores), Libro homenaje al profesor Manuel Albaladejo García, Tomo I (Murcia, Colegio de registradores de la propiedad y mercantiles de España). 
AMAT LLARI, María Eulalia (1990): "La regulación de las inmisiones en el CC", en AA.VV, Centenario del Código Civil, Tomo I (Madrid, Editorial Centro de Estudios Ramón Areces): pp. 73-99.

Amunátegui Perelló, Carlos Felipe (2012): "Las relaciones de vecindad y la teoría de las inmisiones en el Código Civil" en Revista de Derecho de la Pontificia Universidad Católica de Valparaiso, vol. XXXVIII, $\mathrm{N}^{\circ}$ 1: pp. 77-120.

Amunátegui Perelló, Carlos Felipe (2013): Derecho Civil y medio ambiente. Un estudio de la teoría de las inmisiones y su aplicabilidad en el Derecho chileno (Santiago, Thomson Reuters).

Amunátegui Perelló, Carlos Felipe (2013): "Hacia un concepto de inmisiones en el Derecho chileno", en Revista Chilena de Derecho, vol. XL, N 1: pp. 46-86.

Claro Solar, Luis (1930): Explicaciones de Derecho Civil y Comparado. De los bienes. Tomo VI (Santiago, Imprenta Nascimento).

CUAdrado PÉREZ, Carlos (2005): Ruido, edificación y edificaciones (Madrid, Editorial Reus).

EMBID TELlo, Antonio Eduardo (2010): Precaución y Derecho. El caso de los campos electromagnéticos (Madrid, Iustel).

EVANGELIO LlORCA, Raquel (2000): La acción negatoria de inmisiones en el ámbito de las relaciones de vecindad (Granada, Comares).

Hedemann, Justus Wilhelm (1955): Tratado de Derecho Civil, traducción española y notas de José Luis Diez Pastor y Manuel González Enríquez, vol. II (Madrid, Revista de Derecho Privado).

Hualde MANSO, Teresa (2004): “Inmisiones provocadas por establecimientos industriales autorizados (Comentario a la sentencia T.S.J. de Navarra, de 3 de mayo de 2004)", Revista Jurídica de Navarra, No 39: pp. 177-192.

JiMÉNEZ SALCEDO, María Carmen (1999): El régimen jurídico de las relaciones de vecindad en el Derecho romano (Córdoba, Universidad de Córdoba).

Pescio V., Victorio (1950): Manual de Derecho Civil. De las personas, de los bienes y de la propiedad, Tomo III (Santiago, Editorial Jurídica de Chile).

Tisné Niemann, Jorge Bertrand (2017): Las inmisiones. Protección de la propiedad frente a ruidos, humos, olores y otros conflictos de vecindad (Santiago, Thomson Reuters).

Westermann, Harry et al. (1998): Derechos reales (Madrid, Fundación Cultural del Notariado, séptima edición).

\section{NORMAS CITADAS}

CONSTitución Política de Chile.

CÓdigo Civil CHILENO.

CÓdigo CiVIL ALEMÁN.

CÓdigo Civil austriaco.

Código Civil de Cataluña, España.

CÓdigo Civil y COMERCIAL ARGENTINO.

CÓdigo CIVIL PARAgUayo. 


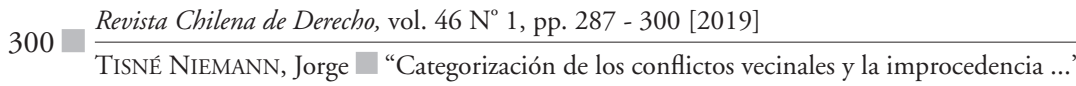

CÓdigo de Aguas CHILENO.

LEY N $N^{\circ} 19.925$ (19/1/2014), Ley sobre expendio y consumo de bebidas alcohólicas.

LEY No 19.880 (29/5/2003), Establece bases de los procedimientos administrativos que rigen los actos de los órganos de la Administración del Estado.

\section{JURISPRUDENCIA CITADA}

RODRÍGUEZ Y OTROS CON INMOBILIARIA SOCOVESA SUR S.A. (2017): Corte de Apelaciones de Puerto Montt, 26 de abril de 2017, Rol N²776-2016 (Recurso de protección).

RODRÍGUEZ Y OTROS CON INMOBILIARIA SOCOVESA SUR S.A. (2018): Corte Suprema, 15 de marzo de 2018, Rol № 18.218-2017 (Apelación a recurso de protección).

RUiz CON RESTAURANT COMIDA Y SABOR Y OTROS (2015): Corte de Apelaciones de Puerto Montt, 25 de mayo de 2015, Rol No 91-15 (Recurso de protección), disponible en Microjuiris MJCH_MJJ41665. 